Resenhas 



\section{Milton e Blake em Paraiso Reconquistado}

MILTON AND BLAKE IN PARADISE REGAINED

Juliana Steil

Universidade Federal de Pelotas, Pelotas, RS, Brasil

MILTON, John. Paraíso Reconquistado. Tradução de Guilherme Gontijo Flores (coordenador), Adriano Scandolara, Bianca Davanzo, Rodrigo Tadeu Gonçalves e Vinicius Ferreira Barth. Ilustrações de William Blake. São Paulo: Editora de Cultura, 2014.

\section{MILTON E BLAKE EM PARAÍSO RECONQUISTADO ${ }^{1}$}

Aparentemente, os temas e técnicas do poeta seiscentista inglês John Milton (1608-1674) não interessariam, em princípio, à literatura contemporânea. Não haveria afinidade poética com a sensibilidade atual, e não há unanimidade sobre a posição do autor de L'Allegro e Il Penseroso no paideuma do século XXI mesmo entre instituições de língua inglesa. Em língua portuguesa, porém, sua obra tem recebido considerável atenção de tradutores e editores nos últimos anos.

Como não poderia deixar de ser, Paradise Lost (publicado inicialmente em 1667, ganhando uma edição revista em 1674) é o livro de Milton mais discutido e traduzido em língua portuguesa. Há, pelo menos, cinco traduções deste poema para o português europeu - três em prosa e duas em verso - e duas para o português brasileiro, ambas em prosa, além de uma tradução parcial do poema em verso branco².

À parte a tradição em torno de Paradise Lost, estão surgindo no Brasil traduções de textos menos comentados de Milton, como os poemas em latim e grego, que foram traduzidos por Erick Ramalho (Poema-

1. Agradeço a leitura atenta e as sugestões do professor Walter Carlos Costa.

2. De acordo com a pesquisa de Fernandes ("Paradise Lost em português", TradTerm, vol. 20, 2012), as traduções em português europeu são as de Padre Antônio Amaro da Silva (1789, em prosa), Francisco Bento Maria Targini (1823, em verso), António José de Lima Leitão (1840, em verso), Fernando da Costa Soares e Raul Domingos Mateus da Silva (2002, em prosa) e Jonas Daniel (2006, em verso). Em português brasileiro, são conhecidas as traduções em prosa de Conceição Garcia Sotto Maior (1946), Paulo Matos Peixoto (1995) e a tradução parcial de Fabiano Seixas Fernandes (2011).

Uma edição brasileira da tradução de Targini está sendo preparada por Guilherme Gontijo Flores. 
ta, Tessitura, 2009), e Paradise Regained, publicado pela primeira vez em português brasileiro em tradução realizada por Guilherme Gontijo Flores (coordenador), Adriano Scandolara, Bianca Davanzo, Rodrigo Tadeu Gonçalves e Vinicius Ferreira Barth (Editora de Cultura, 2014).

Paradise Regained, a breve epopeia estruturada em quatro seções (uma obra experimental, praticamente sui generis, na opinião de Frye “The typology of Paradise Regained", 19653) e publicada originalmente em 1671, no mesmo volume onde se publicou Samson Agonistes, é, como se sabe, uma continuação a Paradise Lost. É possível dizer que ambos os poemas seguem uma mesma linha narrativa em torno do tema da tentação: em Paradise Lost, o primeiro homem sucumbe à serpente e, nos termos da justiça divina, perde sua morada paradisíaca; em Paradise Regained, o Filho 316 de Deus, nascido de mulher, enfrentará, de modo semelhante a Jó, as provações oferecidas por Satanás, e, finalmente, triunfará sobre a serpente, recuperando, portanto, a árvore e a água da vida antes perdidas. A ligação é clara, e a reconquista do paraíso já se anuncia na abertura de Paradise Lost ("With loss of Eden, till one greater Man/ Restore us, and regain the blissful Seat" - Paradise Lost, Book I: 5-6).

Assim como Paradise Lost aproveita a estrutura concisa do Gênesis para propor uma descrição mais ampla da queda, Paradise Regained desenvolve um quadro mais detalhado da tentação de Cristo no deserto inspirado no texto de Mateus, Marcos e, especialmente, Lucas (4, 1-13). A base bíblica fornece os traços gerais da narrativa na forma das três tentações de Satanás a Cristo: “1) ceder à fome e aceitar os alimentos produzidos por ele, Satã (livros I e II); 2) usar seu poder para ter soberania secular sobre os homens e, por fim aceder à glória; e 3) lançar-se do alto do pináculo do tempo de Jerusalém, com a confiança de que será salvo pelos anjos", como sintetizam Flores, Scandolara e Barth no posfácio a Paraíso Reconquistado (p. 249). O motivo de Milton escolher o episódio da tentação no deserto como o momento da vitória final de Cristo sobre Satã recebeu diferentes interpretações da crítica. Frye (1965) afirma que a decisão de Milton decorre de sua recusa das referências bíblicas sobre a descida do Salvador aos infernos após a crucificação; Wittreich (Angel of Apocalypse - Blake's Idea of Milton, 1975, pp.127-128), por sua vez, argumenta que

3. O célebre ensaio de Frye foi consultado no volume Milton - Modern Essays in Criticism, editado por Arthur E. Baker (Oxford University Press, 1965). 
Milton quis, com a omissão da paixão e crucificação, simplesmente eliminar a tortura e o horror do cristianismo, e deixar para trás a lei do sacrifício do Antigo Testamento.

Toda a sequência de tentações desenvolve-se na estrutura de uma batalha verbal, segundo o virtuosismo argumentativo que é uma das marcas de Milton. Assim, o conflito entre Satã e Cristo não é físico - embora o campo de batalha do espírito seja o corpo físico -, mas intelectual, como observa Frye (1965, p. 430), sendo as armas as da dialética, e o dragão a ser vencido, um inimigo espiritual. Nesta jornada, Jesus iria libertar-se da obediência à lei para entregar-se às obras da fé (FRYE, 1965, p. 432).

No prefácio de Milton a Poem, William Blake (1757-1827) escreve alguns de seus versos mais conhecidos:

Milton e Blake em Paraíso Reconquistado

I will not cease from Mental Fight,

Nor shall my Sword sleep in my hand:

Till we have built Jerusalem,

In Englands green \& pleasant Land

(ERDMAN [editor], The Complete Poetry and Prose of William Blake, 1988, pp. 95-96)

É nos termos de um combate contra as forças da Razão restritiva, por meio de guerras intelectuais, que o poeta, pintor e gravurista londrino, profundo conhecedor da obra de Milton, fundamenta o seu ideal de poesia, encontrando na Bíblia o seu modelo máximo. Para ele, a Bíblia é o Código dos Códigos de Arte, a grande obra de Imaginação ${ }^{4}$, onde as narrativas são conflitos espirituais, em oposição a obras clássicas gregas e romanas, que se ocupam de temas bélicos, voltados para a realidade material, o que mostraria a influência de Satã.

Quando o assunto é Paradise Lost, menciona-se frequentemente o excerto de The Marriage of Heaven and Hell em que Blake afirma a inclinação de Milton para o ponto de vista do demônio ${ }^{5}$. É preciso lembrar que a figura de Satã apresenta variações ao longo da obra de Blake - ela pode representar uma carga positiva no contexto de sua mitologia, como energia ativa que se rebela contra forças repressoras, ou, ao contrário,

4. "The Old \& New Testaments are the Great Code of Art/ Jesus \& his Apostles \& Disciples were all Artists" (ERDMAN, 1988, p. 274).

5. "The reason Milton wrote in fetters when he wrote of Angels \& God, and at liberty when of Devils \& Hell, is because he was a true Poet and of the Devils party without knowing it" (ERDMAN, 1988, p. 35). 
uma representação da tirania. $\mathrm{O}$ excerto de The Marriage of Heaven and Hell sugere a interpretação positiva de Satã e reflete a antipatia de Blake em relação à figura de Deus em Paradise Lost, por ele considerado um tirano.

A tendência romântica de ver a figura de Satã de forma positiva ajuda a explicar o seu destaque em ressonâncias do poema de Milton, mas a sua fama como personagem central se desenha, em grande parte, porque o papel de Satã é muito ativo e ele, afinal, é vitorioso em seu plano de tentação. De todo modo, na perspectiva de Blake, Paradise Lost é a obra onde Milton apresenta o "evangelho da punição"; em Paradise Regained, contudo, Milton coloca em relevo a figura de Cristo, realizando a sua visão do "evangelho do perdão" (WITTREICH, 1975, p. 43). Nesse sentido, Paradise Regained não pode ser lido como um complemento ou apêndice de Paradise Lost, uma vez que ele 318 representa o último e verdadeiro posicionamento de Milton: a palavra final do poeta profeta é a vitória arrasadora de Cristo sobre Satã-Urizen, o inimigo interior na jornada espiritual para a redenção da humanidade.

Ao abordar as ilustrações de Blake para os poemas de Milton, Wittreich chama o primeiro de "ilustrador-crítico". Isto porque as ilustrações de Blake têm uma função interpretativa que vai além da ilustração literal dos textos originais. Em geral, há consenso de que Blake destaca a figura de Cristo em suas últimas ilustrações para Paradise Lost. Para Wittreich, o artista, com suas ilustrações a Paradise Regained, que apresenta Cristo como herói supremo, continua o seu projeto de ajustar a situação da obra de Milton na tradição literária e cristã. Neste projeto, Blake enfatiza a superação da antiga ortodoxia - bastaria considerar, por exemplo, a demonização do batismo de Cristo na primeira ilustração da série, em que João olha para Satã, e não para Jesus, ao realizar o ritual (WITTREICH, 1975, p. 133).

A presença das doze ilustrações de Blake a Paradise Regained na edição de Paraíso Reconquistado, não poderia, pois, ser mais coerente, uma vez que ela mostra a relevância do poema no conjunto da obra de Milton.

Além da reprodução das ilustrações de Blake, acompanhadas de breves comentários, a edição bilíngue de Paraíso Reconquistado traz um texto de "Introdução", escrito por Guilherme Gontijo Flores, Adriano Scandolara e Vinicius Ferreira Barth e dividido em duas seções: a primeira informa sobre a vida e a obra de John Milton, e a segunda descreve o projeto de tradução de Paradise Regained. Esta segunda seção expõe o processo de uma tradução literária coletiva, o que de fato "não é uma prática muito comum" (p. 18), e explora o interior do material poético de Milton. 
Flores, Scandolara e Barth explicam que a tradução de Paradise Regained se realizou a partir de uma disciplina sobre Paradise Lost ministrada por Flores no bacharelado em tradução do curso de Letras da UFPR (p. 19). O grupo de cinco tradutores fez a divisão dos versos em partes iguais para uma primeira fase de trabalho individual e definiu critérios bastante específicos. 0 metro utilizado na tradução seria o decassílabo, "sáfico ou heróico, mas, de qualquer modo, evitando-se sílabas tônicas em posição de $5^{\mathrm{a}}$ ou $7^{\mathrm{a}}$, a fim de ser produzido um efeito semelhante ao dos pés jâmbicos" (p. 19). Esta opção indica uma abordagem do ritmo centrada na regularidade; os comentários sobre a tradução não mencio-

Milton e Blake em Paraíso nam o repertório de desvios e sua função expressiva no poema original ${ }^{6}$. A abertura do poema - provavelmente o trecho mais reelaborado na fase de revisão coletiva da tradução, como relata a "Introdução" (p. 21) - pode ser uma amostra de como os tradutores procederam em relação à estrutura métrica:

\section{Reconquistado}

Eu, que há pouco o feliz Jardim cantei,

Perdido em desobediência, canto

Aos homens recobrado Paraíso,

Provada a obediência de outro homem

Por toda a tentação, o Tentador

Frustrado em seus ardis, vencido e expulso,

E o Éden ressurgido em vasto ermo.

(p. 55)

I, Who erewhile the happy Garden sung

By one mans disobedience lost, now sing

Recover'd Paradise to all mankind,

By one mans firm obedience fully tri'd

Through all temptation, and the Tempter foil'd

In all his wiles, defeated and repuls't,

And Eden rais'd in the waste Wilderness.

(p. 54)

\footnotetext{
6. Paulo Henriques Britto apresenta uma discussão sobre a variação rítmica no pentâmetro jâmbico e sua tradução para o português no artigo "Padrão e desvio no pentâmetro jâmbico inglês: um problema para a tradução" (em GUERINI, TORRES \& COSTA (orgs.) Literatura traduzida e literatura nacional, 7Letras, 2008). Entre os autores que discutem as variações características do pentâmetro jâmbico de Milton estão Grace Eva Hunter (The Development of Milton's Prosody, State University of Iowa, 1921) e Martin J. Duffell (A New History of English Metre, Modern Humanities Research Association and Maney Publishing, 2008).
} 
O sistema da tradução refaz o estilo imponente, embora por certo menos apaixonado e menos ornado (do que o estilo de Paradise Lost, no caso), de Paradise Regained, apresentando trechos magnéticos, como nesta sequência em que Satã insiste na oferta do trono do mundo a Cristo, no quarto livro:

\section{Juliana Steil}

Que fazes afinal no mundo? Um ermo

É o que melhor te cabe, aqui te encontro,

E para cá retorno-te; recorda

O que prevejo: logo vem motivo

Para que te arrependas da recusa,

Por cuidado que seja, à minha ajuda;

Que em breve tempo fácil te alçaria

Ao trono de Davi, trono do mundo,

Na tua madurez, melhor sazão

Por que melhor se cumpra a profecia.

Ao contrário, no céu se nada leio,

Se o céu não 'screve o fado, pelos astros

Em grupo, ou caracteres isolados

Em conjunção, agora eu te soletro:

Tristezas, sofrimentos, rixa e ódio

Te guardam, zombaria, escárnio, mofas,

Violência e, por fim, morte cruel.

(p. 191, 193)

What dost thou in this World? the Wilderness

For thee is fittest place, I found thee there,

And thither will return thee, yet remember

What I foretell thee, soon thou shalt have cause

To wish thou never hadst rejected thus

Nicely or cautiously my offer'd aid,

Which would have set thee in short time with ease

On David's Throne; or Throne of all the world,

Now at full age, fulness of time, thy season,

When Prophesies of thee are best fullfill'd.

Now contrary, if I read aught in Heaven,

Or Heav'n write aught of Fate, by what the Stars

Voluminous, or single characters,

In their conjunction met, give me to spell,

Sorrows, and labours, opposition, hate, 
Attends thee, scorns, reproaches, injuries,

Violence and stripes, and lastly cruel death,

(p. 190, 192)

O projeto de tradução permitiu "neologismos, preciosismos e jogos de palavras" (p. 20), de fato utilizados com moderação no texto em português, conforme o acordo feito entre os tradutores. Os neologismos, em particular, refletem algo do estilo concreto de traduzir, não sem algum vestígio do léxico homérico de Odorico Mendes:

Dar-me o que é meu, num pacto desprezível,

P'ra que eu recline e te venere um Deus?

Vai de retro, que agora apareceste,

Milton e Blake

em Paraiso

Reconquistado

ó maligno, Satã sempidanado

(p. 179)

To me my own, on such abhorred pact,

That I fall down and worship thee as God?

Get thee behind me; plain thou now appear'st

That Evil one, Satan for ever damn'd.

(p. 178)

Depois de dira noite, aurora bela,

Em cinza amito, em passos peregrinos,

Que dedirradiante rasou o urro

Do trovão, caçou nuvens, deitou ventos

E espectros vis, gerados do Demônio

Pr'a com terror tentar o Divo Filho.

(p. 195, 197)

Thus pass'd the night so foul till morning fair

Came forth with Pilgrim steps in amice gray;

Who with her radiant finger still'd the roar

of thunder, chas'd the clouds, and laid the winds,

And grisly Spectres, which the Fiend had rais'd

To tempt the Son of God with terrors dire.

(p. 195, 196)

A criação premeditada de "palavras paroxítonas de duas sílabas para adjetivos de três, como 'glório'e 'bárreo"' (p. 20), e também as contrações, como "p'ra" e “'screve", sinalizando processos de acomodação, 
certamente favoreceram a manutenção do padrão métrico escolhido. Distorções sintáticas também foram utilizadas (p. 20), um recurso que evidentemente corresponde à natureza da sintaxe miltoniana, em parte definida pela interferência do latim. Em relação a questões gráficas, foram feitas "inserções de aspas para indicar as falas" e se utilizaram "maiúsculas apenas para nomes próprios ou de maior relevância" (p. 21). O número de versos da obra (2.070) foi mantido (p. 20).

Além da "Introdução", a edição de Paraíso Reconquistado traz notas críticas a cada livro, indicando o intertexto bíblico, entre outros elementos, e o posfácio já mencionado, "Da perda à reconquista", dirigido a um público pouco familiarizado com a obra, em que Flores, Scandolara e Barth discutem a composição, a temática, a recepção e o gênero de Paradise Regained.

Paraíso Reconquistado mostra, em edição elegante, o resultado de um projeto de tradução criterioso. Sem dúvida, a tradução coletiva obteve sucesso, como atesta, principalmente, a sua qualidade técnica em relação à proposta estabelecida.

No contexto da literatura brasileira contemporânea, Paradise Regained pode interessar pelo aspecto universal de sua temática, como um ponto de vista sobre o destino da humanidade, ou, em interpretação alternativa, sobre a conduta individual. Em termos de composição, a tradução da obra de Milton pode ser considerada um exercício de experimentação de elementos poéticos clássicos. Esta hipótese pode indicar o retorno do interesse em formas fixas como fator de inovação ou revitalização do repertório poético nacional. 